\title{
Listas de 1900 utentes: a quantidade questiona a qualidade
}

Raquel Braga*

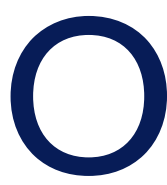

Serviço Nacional de Saúde está a mudar e não há dúvidas que se avizinham tempos ainda mais difíceis para os médicos de família.

A juntar às dificuldades já sentidas, devidas à gestão da complexidade da consulta e aos exigentes objectivos alvo de contratualização com as Unidades de Saúde e Agrupamentos de Centros de Saúde (ACeS), temos agora a imposição, para quem opte ou tenha forçosamente de aderir ao regime das 40 horas/semana, de trabalhar com listas de 1.900 utentes, correspondentes a 2.358 unidades ponderadas. Este tipo de regime de trabalho, que para os médicos de família já contratados é opcional, a partir de 2013, é obrigatório para todos os novos contratos. ${ }^{1}$

Podemos encarar esta como uma das maiores cedências do acordo estabelecido a 14 de Outubro de 2012 entre os Sindicatos Médicos, o Ministério da Saúde e o Ministério das Finanças que, afectando de entre a classe médica apenas os médicos de família, vai permitir minorar um problema grave a nível da política de saúde, através da atribuição de médico de família a mais de um milhão de utentes.

No entanto, apesar de teoricamente minimizar esse problema, é fácil antever que condicionar o trabalho com listas desta magnitude irá acarretar menor acessibilidade, menos tempo para a consulta, menor qualidade no atendimento dos utentes, menos tempo para tarefas preventivas e de promoção da saúde, menos tempo para tratar problemas de doença aguda e crónica, menor satisfação dos médicos e dos utentes e provavelmente maiores gastos com exames complementares de diagnóstico e com a prescrição.

Outro aspecto importante deste aumento do número de utentes a atender será a implicação na formação

*Directora da Revista Portuguesa de Medicina Geral e Familiar de médicos internos. Com esta sobrecarga tornar-se-á mais difícil e haverá menos tempo para fazer uma formação orientada e reflectida, pois a azáfama entre o doente que sai e o doente que entra estreitará o tempo disponível para acompanhamento dos formandos, sobretudo os que estão na fase inicial da sua formação específica. Ou seja, esta medida irá ter repercussão directa na capacidade formativa dos serviços e, desde já, é de alertar para isto o Colégio da Ordem dos Médicos e as Coordenações de Internato.

Num dia-a-dia atarefado, em que lutamos para manter acessibilidade e a qualidade das consultas, para além do cumprimento dos indicadores contratualizados, o atendimento de tamanha quantidade de utentes, sem que se materialize ou preveja o reforço do apoio de outros profissionais de saúde a breve prazo (como secretários clínicos dando apoio efectivo à actividade do médico, psicólogos, nutricionistas, podólogos, enfermeiros diferenciados em determinadas áreas de intervenção prioritária com real partilha das actividades da consulta, etc.) pode transformar-se numa tarefa simultaneamente hercúlea e frustrante, pois ao acréscimo de esforço pode juntar-se uma sensação de trabalho menos conseguido e de inferior qualidade.

Para agravar esta situação, acresce que, a 24 de Outubro de 2012, foi decretado expurgar automaticamente as listas de utentes, até aqui com percentagens variáveis de doentes inactivos, em listas com taxas de $100 \%$ de utilização a 3 anos. ${ }^{2}$ Esta condicionante parece vir contrariar a «Explicação do Acordo e das medidas nele inseridas», ${ }^{3}$ efectuada pela Federação Nacional dos Médicos (FNAM), que explicita que «as listas de utentes serão objecto de uma metodologia clara de actualização com a participação dos médicos de família e sem a existência de supostos utentes 'adormecidos' como subterfúgio para aumentar indiscriminadamente o seu 
número global». ${ }^{3}$

Podemos calcular que o aumento das listas para 1.900 utentes por médico de família se vai traduzir num aumento de cerca de mais 800 utentes activos, para listas médias de $1550 \ldots$ tendo em conta a possibilidade de activação automática de uma média de cerca de $30 \%$ de utentes «adormecidos».

Se para listas de cerca 1.550 utentes, há estudos ${ }^{4}$ que demonstram que o tempo é escasso para todas as tarefas a efectuar (entre as tarefas preventivas, de cumprimento dos indicadores, para além das necessárias respostas a situações de doença crónica e aguda), que dizer acerca do volume de trabalho que vai acrescer com tão avultado número de utentes, todos eles activos?

Em outros países, a experiência de trabalho com listas de grandes dimensões é variável, mas diversos estudos $^{5,6}$ já demonstraram os problemas associados à falta de tempo na consulta devidos à sobrecarga condicionada pela necessidade de atendimento de um elevado número de utentes.

Verifica-se que quanto maior é o número de horas assistenciais dedicadas e o tempo disponibilizado por consulta e quanto menor a percepção do médico acusar stress laboral, tanto maior é a satisfação sentida pelo doente relativa aos cuidados recebidos.?

Há também estudos ${ }^{5}$ que apontam para o facto de os médicos que fazem consultas mais longas, prescreverem menos e empenharem-se mais em actividades de promoção da saúde e relembre-se que este último tipo de investimento se pode traduzir, a médio prazo, em estilos de vida mais saudáveis e menor consumo de cuidados médicos. Do mesmo modo, estes médicos atingem níveis mais elevados de capacitação e melhores resultados em alguns dos parâmetros da satisfação dos utentes. As diferenças encontradas não se restringem a resultados de consultas individuais, mas referem-se também a marcadores de longo prazo, que sugerem que os médicos que fazem consultas mais rápidas não conseguem compensar as deficiências relativas à falta de tempo na consulta, fazendo consultas mais frequentes. $^{5}$

Aprender com a experiência dos outros é sinal de inteligência, precaução e sabedoria. Por outro lado, res- ponder a um problema com uma solução pouco efectiva pode condicionar um problema ainda maior.

Que ganharão globalmente os doentes com um médico de família ao qual dificilmente terão acesso e que pouco tempo terá para os ouvir atentamente? Que custos, de todos os géneros, nos trarão consultas rápidas e superficiais?

Que ganhos haverá com esta situação que nos conduzirá a médicos exaustos, a doentes insatisfeitos e potencialmente a piores cuidados?

Por agora, em termos de saldo relativo a esta medida tomada, objectivamente ainda só podemos especular sobre os resultados. No entanto, já se ganhou algo... um travo amargo na boca e a sensação incómoda de que as coisas não vão correr bem, nem para nós, nem para os nossos doentes.

\section{CONFLITO DE INTERESSES}

A autora é Presidente do Conselho Clínico do ACeS de Matosinhos

\section{REFERÊNCIAS BIBLIOGRÁFICAS}

1. Governo de Portugal. Ministro da Saúde assina acordo global com sindicatos médicos. Disponível em: http://www.portugal.gov.pt/pt/os-ministerios/ministerio-da-saude/mantenha-se-atualizado/20121015-msacordo-sindicatos.aspx [acedido em 27/10/2012].

2. Despacho n. ${ }^{\circ} 13795 / 2012$. Diário da República, 2. ${ }^{a}$ série — N. ${ }^{\circ} 206$ 24 de outubro de 2012.

3. Federação Nacional dos Médicos. Explicação do Acordo e das medidas nele inseridas. Disponível em: http://www.fnam.pt/comunicados/comunicados_files/acordo_medidas_inseridas.pdf [acedido em 27/10/2012].

4. Pinto D, Corte-Real S, Nunes JM. Actividades preventivas e indicadores Quanto tempo sobra? Rev Port Clin Geral 2010 Set-Out; 26 (5): 455-64.

5. Wilson A, Childs S. The relationship between consultation length, process and outcomes in general practice: a systematic review. $\mathrm{Br} \mathrm{J}$ Gen Pract 2002 Dec; 52 (485): 1012-20.

6. Campbell JL. The reported availability of general practitioners and the influence of practice list size. Br J Gen Pract 1996 Aug; 46 (409): 4658.

7. van den Hombergh $P$, Künzi B, Elwyn G, van Doremalen J, Akkermans R, Grol R, et al. High workload and job stress are associated with lower practice performance in general practice: an observational study in 239 general practices in the Netherlands. BMC Health Serv Res 2009 Jul 15; 9: 118.

\section{ENDEREÇO PARA CORRESPONDÊNCIA}

director@rpcg.apmcg.pt 